\title{
PhD Candidate Expectations: Exploring Mismatch with Experience
}

\author{
Allyson Holbrook, Kylie Shaw, Jill Scevak, Sid Bourke, \\ Robert Cantwell, \& Janene Budd \\ SORTI, Faculty of Education \& Arts, The University of Newcastle, \\ Callaghan, NSW, Australia
}

\author{
Allyson.Holbrook@newcastle.edu.au; Kylie.Shaw@newcastle.edu.au; \\ Jill.Scevak@newcastle.edu.au; Sid.Bourke@newcastle.edu.au; \\ Robert.Cantwell@newcastle.edu.au; Janene.Budd@newcastle.edu.au
}

\begin{abstract}
This paper identifies the nature of initial expectations of $\mathrm{PhD}$ candidates, the prevalence and type of mismatch between expectations and experience, and to what extent mismatch is reflected in satisfaction with candidature. The data were drawn from telephone interviews with a sub-sample of $104 \mathrm{PhD}$ candidates from an initial online national survey of 1,374 candidates at Australian universities. Based on the interviews, eight categories of initial expectations coalesced into three dimensions: the doctoral 'Task', the 'University' (including supervision), and 'Personal' factors. The relationships between candidates' initial expectations and subsequent experience were examined, with specific reference to mismatches that were positive, neutral, or negative (most being negative). Where there was mismatch, this was primarily in relation to what was involved in the 'Task' and the associated emotions. The negative mismatch codes were consistently related to candidate satisfaction with supervision, with department/university provision, and with their own preparation for the degree. Further analyses of experience indicated that negative mismatch caused candidates to question, not necessarily productively, their preparation, purpose, fit, and persona.
\end{abstract}

Keywords: doctoral expectations, mismatched expectations, doctoral candidate experience, doctoral candidature, doctoral satisfaction, research education

\section{Introduction}

$\mathrm{PhD}$ candidates are adult learners with a broad range of educational and career experience (Pearson, Cumming, Evans, MacCauley, \& Ryland, 2011). However, relatively little is known about

Material published as part of this publication, either on-line or in print, is copyrighted by the Informing Science Institute. Permission to make digital or paper copy of part or all of these works for personal or classroom use is granted without fee provided that the copies are not made or distributed for profit or commercial advantage AND that copies 1) bear this notice in full and 2) give the full citation on the first page. It is permissible to abstract these works so long as credit is given. To copy in all other cases or to republish or to post on a server or to redistribute to lists requires specific permission and payment of a fee. Contact Publisher@InformingScience.org to request redistribution permission. candidate expectations when they enter candidature, if these expectations are met, and the impact on the candidate if they are not. Expectations here refer to the candidate's preconceived ideas of what will occur in relation to, or as an outcome of, their candidature. These might range across expectations connected with career and success through to those connected with supervision, the learning environment and demands of 
study (Bieschke, 2000; Pole, Sprokkereef, Burgess, \& Lakin, 1997). There is evidence that misalignment or mismatch between expectations and experience during candidature can lead to dissatisfaction and dropout (Bair \& Haworth, 2004; Gardner, 2009; Golde, 2005). Even so, expectations have not had a high profile in the literature, possibly because there has been a tendency to conflate the expectations of the candidate with those of the institution and discipline. In recent years there has been growing recognition of the need to move beyond the institution and its expectations and recognize what $\mathrm{PhD}$ candidates bring to the degree, including their home and work life, previous research and other knowledge, experience, and priorities. These considerations can shape expectations and are especially important if we are to understand more comprehensively the nature of the individual challenges doctoral learners face and what impedes their progress (Cantwell, Scevak, Bourke, \& Holbrook, 2012; McAlpine, Paulson, Consalves, \& Jazvac-Martek, 2012).

Studies directed at match and mismatch between expectations and experience have tended to focus on supervision or relational support (Hair, 2006; Haksever \& Manisali, 2000; Moxham, Dwyer, \& Reid-Searl, 2013) and academic or program match (Golde, 2005; Hoskins \& Goldberg, 2005), but not so much the expectations of the type and demands of study or the anticipated positives and negatives intellectually and emotionally. In recent research that explores doctoral candidate well-being, Juniper, Walsh, Richardson, and Morley (2012) discovered a broad range of concerns anticipated by candidates about candidature. Prominent among these was concern about the 'experience of research'. Given the potential for unmet or misaligned learning expectations to impede progress or cause distress, it is important to determine more comprehensively what form student learning expectations take and if there are common misconceptions that can be addressed.

This paper directly addresses student expectations about their learning, anticipated experience of doing research, and their identification of the type and direction of any mismatch. Also of interest is whether experience of mismatch is reflected in student satisfaction with candidature. There is some evidence that realization of expectations contributes to satisfaction with doctoral candidature and there is a positive relationship between satisfaction and completion (Bair \& Haworth, 2004). The first section of the paper examines the literature on expectations in postgraduate research, followed by the mixed methods design that was adopted. The design draws on both telephone interviews and a survey, including a description of the analysis process. The results section presents respondent demographics and qualitative findings relating to types and direction of match/mismatch and the experience of mismatch, followed by the statistical analysis that links the direction and type of mismatch identified in the interviews with the satisfaction scales from the survey. The final sections of the paper comprise the strengths and limitations of the study, conclusions and discussion.

\section{Literature Review}

When they come to enrol, $\mathrm{PhD}$ students have already experienced an extended education and have excelled in academic work. Some may be re-entering education after a prolonged absence and many will be engaged in employment during their candidature. Given their diverse ages and backgrounds, it is reasonable to assume that their expectations will be shaped by a range of factors including prior educational experience, exposure to research culture, professional and work experience, family obligations, and personal and social goals (Barnett, Cropley, Hanton, \& Fleming, 2013; Edwards, Bexley, \& Richardson, 2010). Expectations are generally identified as important in understanding doctoral student experience of the learning environment (Lindn, Ohlin, \& Brodin, 2013; Pole et al, 1997) and in influencing satisfaction with course and supervision (Bieschke, 2000; Hair, 2006).

At secondary school level, students' a priori expectations of a new learning environment have been shown to influence the individual's response to that environment and to affect engagement, 
motivation, and investment of effort (Könings, Brand-Gruwel, van Merriënboer, \& Broers, 2008). At undergraduate level, there is evidence that unrealistic expectations about the nature of teaching and learning have a detrimental effect on retention and achievement (Nicholson, Putwain, Connors, \& Hornby-Atkinson, 2013). There are only occasional glimpses in the doctoral literature of the $a$ priori expectations and factors that come into play at the point when an individual actually makes the decision to undertake a research degree (Barnett et al., 2013). While expectations are documented in the literature (McAlpine et al., 2012; Pole et al.. 1997; Spaulding \& RockinsonSzapkiw, 2012), rarely do we get to know, for a typical group, if the experience of doing research was much as expected or very different, and either easier or more difficult than expected.

Many students come back to study quite late, so their ideas of the research environment and intensity of study may be unrealistic. Another potential source of mismatched or unrealistic expectations is change at a systemic level. In recent years there have been changes in enrolment patterns and pathways into doctorates, new types of doctorates, and a pronounced shift in candidate career intentions away from academe (Edwards et al., 2010; Klein \& Rowe, 2008; Pearson et al., 2011; Watts, 2009). Furthermore, there are new pressures facing student researchers brought about by increased student enrolments, uncertain financial conditions for student loans and fees, accelerated pace of research, and new regimes of accountability (Engebretson et al., 2008; Ylijoki, 2013). These changes may give rise to unexpected pressures on the student-supervisor relationship, and study-work-life balance.

It is generally recognised that doctoral candidates may not have the same initial conceptions of research as academic research faculty and some struggle to grasp what is required of them (Gardner, 2009, 2010). If misconceptions persist they may have an adverse influence on progress (McCormack, 2004). Nyquist, Manning, and Wulff (1999) found that where research students' expectations mesh with the demands of the academy, these were readily internalized and positive learning experiences resulted. Where this was not the case, the researchers observed negative or disabling tensions that impeded candidacy or led to drop-out. In a single-institution study on attrition (Gardner, 2009), one fifth of students attributed dropping out to 'wrong fit' or that the degree they were enrolled in 'was not for them'. Their motivation dried up (pp.107-108). In a study of doctoral students in counselling, two areas of match/mismatch in expectations and experience were identified: 'academic' and 'social-personal' (Hoskins \& Goldberg, 2005; see also Spaulding $\&$ Rockinson-Szapkiw, 2012). Academic match was essentially between students' goals and reasons for pursuing the degree. Social-personal was primarily about their 'connections' with the learning community, namely faculty academics and fellow students (Hoskins \& Goldberg, 2005, p. 183).

Typically, the literature warns of the need for clarity of expectations around supervision and establishing clear boundaries (Engebretson et al., 2009; Hair, 2006; Moxham et al., 2013). Even so, while students may accommodate the need to adjust their expectations, the situation may fall well short of their learning needs (McAlpine et al., 2012; Pearson, 2012). In engineering, an early study by Haksever and Manisali (2000) found one of the most significant differences in student and supervisor expectations concerned provision of research-related help. Kandiko and Kinchin (2012) revealed a number of laboratory-based research students had expectations more firmly rooted in product than process, whereas their supervisors' expectations were more oriented to personal development, and this misalignment gave rise to conflict. When supervisors address such misconceptions this has been shown to lead to candidate satisfaction and positive doctoral outcomes (Bair \& Haworth, 2004).

Some work has been undertaken on expectations instruments. Bieschke (2000) produced, refined, and tested a research outcomes expectations scale to further explore the impact of outcome expectations on research behaviours. Hair (2006, p. 10) evaluated an inventory of expectations ('Superqual') for use with supervisors and students "to help diagnose potential problems and to allow the 
relationship between supervisor and student to develop" (p. 22). The 22 item inventory was broad, encompassing facilities, supervision, and conditions along dimensions of "reliability, responsiveness, assurance and empathy" (p. 12), and picked up on "autonomy, constructive criticism and research culture" (p.18). The items were specific to the supervisor role: e.g., "Supervisors at an excellent university will ensure research students eventually become competent autonomous researchers" (p.22). While the work does not seem to have progressed further past the initial evaluation stage, benefits were reported when the inventory item responses were used early in candidature in discussions between students and supervisors.

In summary, expectations can play a role in shaping the student response to the learning environment, and unmet expectations can cast a shadow over the individual's learning experience. There is a largely untested assumption that low levels of satisfaction reflect unmet expectations, and some compelling evidence, cited above, that paying attention to expectations can help reduce attrition, identify barriers to progress, reduce tensions, and attend to student well-being. There are aspects of expectations that have not been mapped, and there is no clear idea whether unmet expectations are the norm. In efforts to enhance student satisfaction and assist students in their learning, there is a need to have a much more comprehensive grasp of the nature and prevalence of unrealistic or unmet expectations.

\section{Aims of the Study}

Having established the potential of expectations to shape the learning experience, and the relative paucity of studies on the topic at doctoral level, this study aims to go further than previous studies in:

- describing doctoral candidate expectations in the context of learning;

- determining the prevalence, focus and direction of mismatch between initial expectations and experience; and

- confirming whether mismatch in expectations is related to satisfaction with candidature.

These aims give rise to questions about the range and focus of initial expectations, the situation and response of candidates when expectations do not align with experience, common categories of mismatch, and whether mismatch can have an impact on candidate satisfaction.

\section{Methodology}

This study is one element of a large, national project on doctoral learning, and specifically metacognitive profiling, funded by an Australian Research Council Discovery Grant. The project drew on a multi-strand design involving 'multi-level utilization' of approaches (Teddlie \& Tashakkori, 2003) with different sub-studies and levels of data aggregation. For this sub-study, two types of data were collected - an online survey (quantitative data) that determined the candidate's metacognitive profile (Cantwell et al., 2012) and candidates' levels of satisfaction with candidature. Approximately four months later, in-depth, semi-structured telephone interviews were conducted by three trained interviewers with a sub-sample of survey respondents who had volunteered to participate in the telephone interviews (qualitative data). The interview attempted to elicit a baseline of learning experience including recall of initial expectations and if these had been borne out by experience.

This paper is based on 1,374 doctoral candidates enrolled at Australian universities who answered the online survey and, specifically, a sub-sample of 104 candidates who participated in the telephone interview. The candidates were at various stages of candidature. 
From the interview data, we sought to identify initial expectations (aim i) and establish if there was a mismatch between expectations and experiences, as well as prevalence (aim ii). This process was expected to be descriptive and exploratory drawing exclusively on the qualitative data because there was no established scale to draw on for expectations specific to learning. If it proved possible to answer aim ii and to accurately identify mismatch, the intention was then to determine if mismatch was reflected in candidate satisfaction (aim iii) comparing cases across matched data sets.

The direction of mismatch, positive and negative, was elicited from the interviews and coded. Intersects using QSR NVivo10 software were performed for the different categories of expectations and mismatch. This data was exported from the software in 'quantitized' form (i.e., as numeric codes) (Teddlie \& Tashakkori, 2003, p. 9) and imported into IBM SPSS Statistic software for integration with the satisfaction survey data.

\section{Interviews}

The main focus of the questions asked of participants in the interview was to establish candidate learning experiences described in their own terms and in whatever context they felt was appropriate (managing their project, strategies used, how they perceived their achievements, the existence of any barriers, understandings of the research process, and reflections on candidature more generally, including supervision). Each candidate was also asked a number of questions that specifically targeted the role of external influences and understandings they brought into candidature, why they were doing the degree, their initial expectations and subsequent experience. It is the latter which is the primary focus of this paper.

The semi-structured interviews, typically one hour in length, were digitally recorded. Consent was obtained prior to interview and full transcriptions were produced and entered into QSR NVivol0 software with individual case links to survey responses. All interview data was de-identified and given the matching survey ID at the point of transcription.

During the first cycle of coding, each interview transcript was coded into core content categories. Coding occurred at the level of sentence and most sentences were coded in parallel at multiple categories. Coding notes were developed during this process. The coding notes assisted the research team to reach agreement on 27 a priori core categories linked to metacognitive profile, background, personal, and candidature characteristics, and to code consistently for these. Some 90 single-spaced pages of text were identified that referred explicitly to initial expectations and subsequent experience, ranging in length from four-five lines to close to one page. This text was typically cross-coded with other core categories. Further coding of that text was then undertaken by two of the authors who determined (with 100 percent agreement), that candidate comments suggested eight sub-categories of expectation that coalesced into three dimensions:

- Task - what was involved in the task; time needed; scope/difficulty

- University - supervision; environment, and

- Personal - expectations about feeling emotion; development and trajectory; study/life balance.

The coded text in these categories was then coded further to capture match or mismatch between candidate's recall of initial expectations and subsequent experiences of candidature in an iterative process of comparison and contrast (Bazeley, 2013, p. 164) with recourse to the full interview text. If a mismatch was identified this was coded as positive (experience was better than expectations); negative (experience was worse than expectations), or occasionally as 'different'. In the latter cases we could not identify the affective dimension, for example, "I expected the PhD to be different from my Masters." This category was not large and excluded from the quantitative analysis with satisfaction data. Some candidates identified more than one instance of a category of 
mismatch but this was not typical. The quantitization of mismatch was by instance of category by case. Once the categorization was complete, the same dataset was explored for 'latent themes' that offered deeper insight into the impact of negative mismatch on the learner and their wellbeing (Braun \& Clarke, 2006, pp. 84-85).

\section{Online Survey}

To address aim iii of the study, candidate levels of satisfaction with candidature were analysed using 16 items across three sub-scales. These were satisfaction with:

- Supervision (My supervisors are supportive of my project);

- Department/ university (I found the faculty induction for new candidates useful; and

- Own preparation (I was well qualified to commence a research degree).

The satisfaction instrument was a component of a larger instrument comprising a total of 21 subscales primarily focused on metacognitive functioning (Cantwell et al., 2012) plus demographic questions.

\section{Results}

\section{Respondent Demographic Information}

A small majority of the 104 respondents who responded to the survey and participated in interviews were female (61\%). Candidates interviewed were evenly spread across three stages of candidature (first year, mid-term, and final stage), with just over half enrolled full time (55\%), and there was a spread of respondents across six broad fields of education (Arts/Humanities, Business, Education, Engineering, Health and Science). The interview sample matched the full sample in terms of age, stage of candidature, type of enrolment, and broad field of education, but included a slightly higher proportion of males compared with the full sample.

\section{Expectations about Candidature}

Most qualitative data does not lend itself to quantification, but the direction or orientation of expectations is one area in this study that allowed an integration of methods. Instances of positive and negative experiences emerged as a possibility when the interview data were transcribed and coding categories were being determined, as shown above. Three types of matches/mismatches were coded (As expected - no mismatch; Mismatch - negative experience; Mismatch - positive experience).

Table 1 provides illustration of the type of comment indicative of the dimensions of 'Task', 'University', and 'Personal' with examples of expectations that were as expected and experiences of mismatch that were negative or positive. The remaining codes (not shown in the table) were either comments where direction of mismatch was not indicated or where no expectations were identified. The bracketed ID refers to candidate number on the survey. 
Table 1: Alignment of expectations of the doctoral task

\begin{tabular}{|c|c|c|c|}
\hline $\begin{array}{c}\text { FOCUS OF } \\
\text { EXPECTATION }\end{array}$ & TASK & UNIVERSITY & PERSONAL \\
\hline $\begin{array}{l}\text { As expected - no } \\
\text { mismatch }\end{array}$ & $\begin{array}{l}\text { I had a decent idea of the } \\
\text { mechanics of it. I teach at } \\
\text { another university }(0940) \\
\text { I felt like after the honours } \\
\text { I had a pretty good idea of } \\
\text { what the PhD would be like } \\
(0947)\end{array}$ & $\begin{array}{l}\text { I had been warned about } \\
\text { supervisors so I was } \\
\text { ready for that (1149) }\end{array}$ & $\begin{array}{l}\text { I was aware occasionally } \\
\text { there would be feelings of } \\
\text { doubt or insecurity about } \\
\text { progress and about validity, } \\
\text { well I've been experiencing } \\
\text { those kinds of ups and } \\
\text { downs ( } 0081)\end{array}$ \\
\hline $\begin{array}{l}\text { Mismatch - neg- } \\
\text { ative experience }\end{array}$ & $\begin{array}{l}\text { The writing is really diffi- } \\
\text { cult...I think I expected } \\
\text { more of myself ...I'm not } \\
\text { really sure if I knew what } \\
\text { to expect (1024) } \\
\text { I certainly didn't expect the } \\
\text { rewrites...I thought I would } \\
\text { do better... I expected it to } \\
\text { flow, to go smooth, I didn't } \\
\text { expect it to be as rocky } \\
(0107)\end{array}$ & $\begin{array}{l}\text { Handling the supervision } \\
\text { has been really difficult } \\
\text { for me and that's some- } \\
\text { thing that I didn't expect } \\
\text { (1259) } \\
\text { I assumed to come in, to } \\
\text { be in a really interesting } \\
\text { scientific community, but } \\
\text { I feel this does not exist, } \\
\text { to me, at this time, here. } \\
(0111)\end{array}$ & $\begin{array}{l}\text { I mean I really have no } \\
\text { life...no opportunity for } \\
\text { any other development...no } \\
\text { teaching yet I have to have } \\
\text { those skills ( } 0756 \text { ) } \\
\text { I knew it would be hard but } \\
\text { I didn't think it would be so } \\
\text { difficult to accommodate } \\
\text { within the whole work/life } \\
\text { balance (0146) }\end{array}$ \\
\hline $\begin{array}{l}\text { Mismatch - posi- } \\
\text { tive experience }\end{array}$ & $\begin{array}{l}\text { I thought it was going to be } \\
\text { harder than what it has ac- } \\
\text { tually turned out to be } \\
(1350)\end{array}$ & $\begin{array}{l}\text { On the good side you get } \\
\text { a lot of support which is } \\
\text { great I didn't expect that } \\
(0098)\end{array}$ & $\begin{array}{l}\text {...because I've got time at } \\
\text { work to work on it I'm re- } \\
\text { laxed about it, less stressed } \\
\text { which I wasn't quite ex- } \\
\text { pecting (0173) }\end{array}$ \\
\hline
\end{tabular}

As evident in Table 2, which reports the numbers of codes by category and expectation, most of the comments noted the candidate had some expectations from the outset and the dominant foci were what was involved in the research ('Task' dimension) and the emotions connected with the work ('Personal' dimension). Overall, where orientation was indicated clearly, mismatch in expectation tended to be negative (49\%) rather than positive (13\%), but $38 \%$ of the comments coded specified no mismatch. The comments registering no mismatch tended to focus on what was involved in the task and the emotions known to arise during candidature, suggesting many candidates had realistic or informed expectations often gained by having sought advice. This interpretation tends to be reinforced further by the $13 \%$ positive mismatch noting experiences were better than expected.

This finding tends to provide some balance in a literature where discussion of experience of mismatch tends to be framed in a negative way. Overall the weight of expectation around the task suggests a focus on learning, which is not surprising given the emphasis of the interview protocol, but is also consistent with the Juniper et al. (2012) finding that research is a key concern for candidates. Despite being given the opportunity to raise any issue, relatively few candidates $(n=13)$ talked about expectations in connection with supervision, and then mostly in terms of disappointment. Supervision was a topic of comment in most interviews but rarely in relation to expectations. 
Table 2: Dimensions of expectations and distribution by orientation or alignment (total instances $=185)$

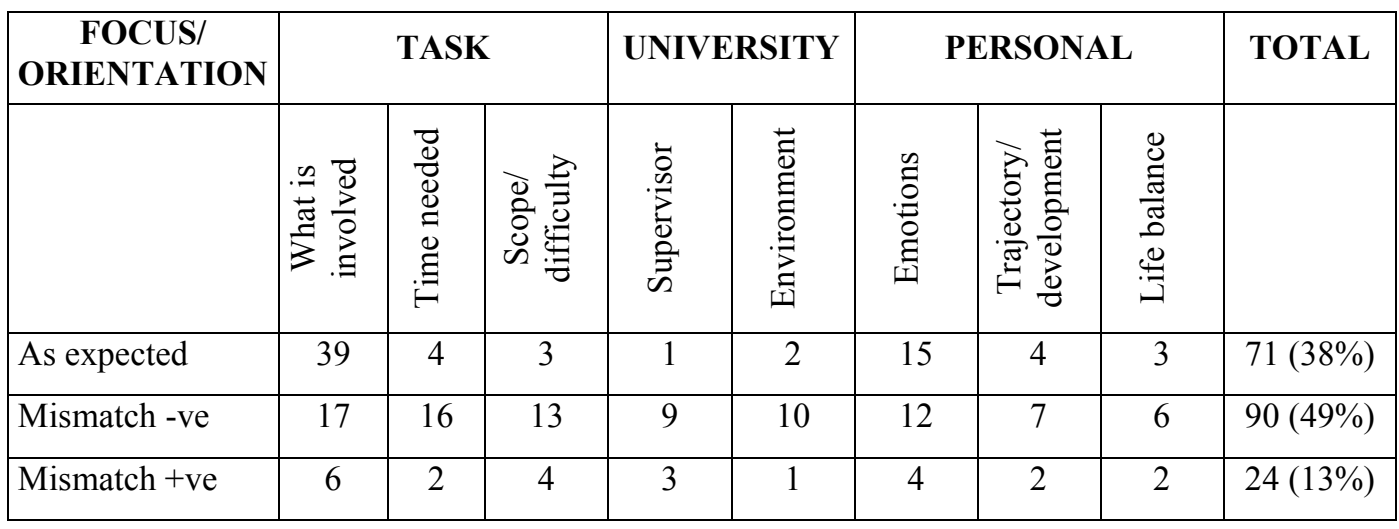

\section{Impact of Mismatch on Individual Candidatures}

Response to mismatch is a highly individual thing. What is unexpected but manageable for one candidate can be experienced in quite the opposite way by another. The way candidates refer to mismatch, and especially where the experience is negative, suggests the likelihood of enduring damage giving rise to strong doubts about the course and their place in it. Some patterns were detected in this text that bear further consideration and research. The first of these themes, labelled "There's preparation and then there's understanding," reflects the degree of surprise candidates feel when they register fundamental misunderstandings about doctoral level work. The second of the themes, "Autonomous and adrift," captures expectations of autonomy including freedom and perceptions of unlimited time that in reality pan out in disappointing and uncomfortable ways. "A complicated existence" reflects the frustrations of those who discover that the degree is not only far from straightforward, but pushes beyond their boundaries. The final theme, the "emotional sink," encapsulates a world that is sliding out of control raising unwelcome questions for candidates as motivation, confidence and energy ebb away.

\section{There's preparation and then there's understanding}

For some candidates there were few surprises about doing research although the following type of comment was rare:

I've worked in university system as an $R A$, no huge surprises ...things like ethics, recruiting people, how slow and painful...I knew I could deal with that kind of stuff (0877)

Many noted they felt prepared through other research courses. They clearly expected a bigger project at doctoral level, something more meaty and challenging.

I had a pretty good understanding of what was involved as far as depth,...I knew it had to be new and innovative... my Masters degree was really quite structured for people ...to go on to do more (1361)

It took a year to get into it I think how it is now is how I imagined it (0144)

$\mathrm{PhD}$ candidates anticipate tough patches because of the level of the degree. Even so, the effort, the challenges and the sheer level of difficulty had the capacity to surprise and supplant previous notions:

Based on my Honours work I was expecting it, but what I found from a PhD is that it is a learning process, you do a study, the results aren't what you expected, you have to re-think...I 
wasn't really prepared for the challenges. I also had this idealised notion of research...it's much, much, more difficult (0563)

It takes me too much time and a lot of effort to reach this point ... I actually have some experience publishing in my old language... (it has been) totally unexpected because it was so difficult (0111)

If someone had told me what I'd have to go through to get to this point I might have potentially reconsidered actually doing it ...you don't realise how difficult it really is... a lot tougher expectations (0189)

Even those candidates who knew from peers what the experience could be like, found that it was difficult to envisage the enormity of the task as it was so different to anything they had done before. They had to experience it to fully understand.

I don't think I had expectations of what it was going to be like. My best friend who has done her PhD said to me, don't do it [name] it will ruin your life...I guess I perhaps was not quite aware of just how unstructured and independent it would be. I suppose I had nothing to kind of attach it to. So I had nothing to compare it to (1372)

\section{Autonomous and adrift}

While some candidates do not realize that the responsibility for learning is theirs (Cantwell et al., 2012), others do not expect problems with being 'autonomous' and look forward to it. Their expectations may be dashed, however, if they experience less than ideal circumstances. One candidate noted grumpily that he had expected to be autonomous, not to be at the 'whim of others' (1135). Most others who commented in this vein, especially in the context of supervision and the learning environment, felt they were more 'on their own' than they had imagined possible, even to the point of being cast adrift and 'abandoned':

I expected the supervisors would be quite directive in helping and supporting me...it's never been there or it has been in a fairly off-handed manner (0146)

I got a lot of support in Honours, the level of difficulty in trying to get support for a PhD from the school is surprising, you would have thought they would be more helpful not a lot less helpful ...I don't feel included at all. (1259)

Time and planning took on a new character as candidates entered the degree feeling they had plenty of time only to realise that, with a few exceptions, the nature of the task drew on time in ways they had definitely not expected and for which they were held accountable, yet were not entirely in control. This extended to research processes that interfered with delivering a product:

I didn't think that I would waste as much time as I have, although they [supervisors] don't call it waste...doing experiments that just aren't going to be included in the final product (0225)

I did well in all the previous levels so I just expected this to continue...expected more specific guidance to reduce levels of uncertainty...stage by stage, rather than the constant questioning, criticism, rethinking everything, going off on tangents (0750)

As indicated above many were floored by the discontinuities they experienced in their expectations about knowledge and scholarship. They expected to find answers, to produce a completed work in plenty of time, when what they faced was a sense of being out of control, and a seemingly never-ending cycle of unfinished business. 


\section{A complicated existence}

One of the realities of candidature is that there is more to becoming a researcher than doing the research. The big shift from being a candidate to becoming a researcher was identified through the interviews. The $\mathrm{PhD}$ was not just more and longer, but quintessentially different, as also revealed in work about epistemological change and scholarly transformation (Cantwell et al., 2012).

There were additional expectations that were sometimes seen positively, for example, some candidates were pleasantly surprised that they were expected to be publishing early in their candidature and were networking broadly as deemed important in the personal and professional devel opment. Others did not value such expectations and construed them less positively and as a distraction:

The amount of networking involved - I didn't expect that ...there isn't as much freedom as you'd think...I went in with an idealistic impression ...I found it difficult to adjust...certain expectations don't mesh well with me. (0674)

'Red tape' (1010), 'paperwork' (0178) and administration were raised in negative terms including ethics applications and the day-to-day running of data collection.

For some what had started as a deep desire to grow and discover was thwarted by the expectations of supervisors and the 'system' and gave rise to the feeling of being robbed of deeper satisfaction or good fit. Some also felt they were being shaped in unwanted ways:

I was expecting to feel a sense of progress ... understanding of deeper philosophical issues...I feel like I'm only writing about them to satisfy a certain element of a chapter (0842)

My targets didn't hold up to the experiments in the way we'd anticipated...I was expecting it to be challenging... rewarding...I hadn't anticipated how I'd be shaped by the PhD (0117)

\section{The emotional sink}

Quite a number noted they had sought advice from other candidates. Many of these had received a 'heads-up' on the 'emotional roller coaster' and knew they would experience some stress and so, when it came, it was not wholly unexpected:

I felt stressed but I knew that's the way it would work (0886)

I'm not at the point where I want to chuck it in, and I'm not at a point where I'm absolutely ecstatic, and that's how I probably felt I would be midway through...so its living up to my expectations (0114)

For others the intensity of emotions they felt was a shock:

You kind of expect this undulating roller coaster, as opposed to the loop the loop style of how you can be so up at one point and then come crashing down within a couple of hours... the turbulence of that emotion I didn't expect (0146)

There are frequently stories of mismatch in expectations that extend into reduced self-efficacy, depression and unwelcome change in behavior:

I had enrolled in a PhD before... unprepared for personal journey...the process of it doesn't live up to my expectations and makes me wonder if they are realistic... whether I'm working at the appropriate level (0778)

I was prepared for it to be hard intellectually... but no one said to me that it is really isolating and that depression is really a big factor in PhD student's lives...I would have really liked someone in the faculty who could have given me more emotional support (0155) 
I was a stable kind of girl...since doing the PhD everything knocks me...I didn't expect it at all (1024)

Doctoral candidates typically enter their studies with very considerable passion for learning and being a student. As evident in the examples above, in small and large ways those experiencing mismatch in negative terms were grieving the loss of their passion and momentum. For some, as the next quotation illustrates, even the satisfaction that accompanied achievement had evaporated:

Emotions... I expected mine to be different but clearly not...like completing confirmation you expect to be happy ... you just feel kind of down...post-confirmation blues (0722)

The major focus of the next section of the paper is to compare candidate interview responses related to their expectations concerning the dimensions of 'Task', 'University' and 'Personal' with candidate scores on the satisfaction scales. This analysis will explore the connection between each candidate's initial expectations of the $\mathrm{PhD}$ and the general level of satisfaction with their candidature.

\section{Relationships between Matches and Mismatches of Expectation/Experience and Candidate Satisfaction}

Doctoral candidate satisfaction with their course and experience has, for some time, focussed substantially on satisfaction with supervision, with the two being reported as strongly related (see Harman, 2002; Zhao, Golde, \& McCormick, 2007). Having the personal touch, including an interest in the broader life of the individual was one of the most desirable characteristics in a supervisor along with advising and career development in a large study of three disciplines in the USA by Zhao et al. (2007).

While finding satisfaction with supervision to be important for successful candidature, researchers have also reported other aspects as equally or more important. These include the departmental intellectual climate (Trigwell \& Dunbar-Goddet, 2005), employment (Gittings, 2010), and university and/or departmental infrastructure support (Tennant, 2008). Much of the variation in satisfaction with advisers has been attributed to a general decline over the period of candidature related to failure to meet expectations in a number of ways (Russo, 2011). Recent work, albeit not specific to the doctorate, identifies an absence in the satisfaction literature, specifically the effect of emotion on satisfaction (White, 2013).

The three sub-scales of candidate satisfaction used in this study were satisfaction with their 'Supervision', with the 'Department/university' provision, and with their 'Own preparation' for the degree. All the satisfaction scales had satisfactory construct validities and reliabilities. Scale means, standard deviations, and reliabilities are given in Table 3 for the sample of $\mathrm{PhD}$ candidates who completed the survey and for the sub-sample included in the present analyses. Two points should be noted. First, the scale mean scores were high, especially for satisfaction with 'Supervision' although less so for 'Department/university', but all three means were clearly above 3.5, the neutral point of the six-point scale. Secondly, the mean satisfaction scores for the sub-sample were not significantly different from the total sample. Consequently we can say that, for satisfaction, the sub-sample was representative of the total sample. 
Table 3: Candidate satisfaction scales for the total sample $(n=1,374) \&$ for the interview sub-sample $(n=104$, in parentheses $)$

\begin{tabular}{|l|l|c|c|c|}
\hline $\begin{array}{l}\text { SCALE: } \\
\text { SATISFACTION } \\
\text { WITH }\end{array}$ & \multicolumn{1}{|c|}{$\begin{array}{c}\text { INDICATIVE ITEM } \\
\text { CONTENT }\end{array}$} & $\begin{array}{c}\text { SCALE MEAN } \\
\text { (RANGE 1-6) }\end{array}$ & SCALE SD & $\begin{array}{c}\text { SCALE } \\
\text { RELIABILITY }\end{array}$ \\
\hline Supervisor & $\begin{array}{l}\text { Supervisor expertise and } \\
\text { interest present (4 items) }\end{array}$ & $\begin{array}{c}5.16 \\
(5.27)\end{array}$ & $\begin{array}{c}0.94 \\
(0.83)\end{array}$ & 0.886 \\
\hline $\begin{array}{l}\text { Department/ } \\
\text { university }\end{array}$ & $\begin{array}{l}\text { University information, } \\
\text { support \& inclusion are } \\
\text { available (6 items) }\end{array}$ & $\begin{array}{c}4.36 \\
(4.43)\end{array}$ & $\begin{array}{c}0.91 \\
(0.94)\end{array}$ & 0.768 \\
\hline Own preparation & $\begin{array}{l}\text { My preparation, knowledge } \\
\text { and skills are appropriate to } \\
\text { the project (6 items) }\end{array}$ & $\begin{array}{c}4.93 \\
(5.00)\end{array}$ & $\begin{array}{c}0.74 \\
(0.71)\end{array}$ & 0.804 \\
\hline
\end{tabular}

Relationships between the satisfaction measures and the newly-created expectation/ experience variables are now considered through the use of correlation coefficients. The expectation/experience variables used were the quantified coding for negative mismatch (i.e., when the experience was worse than anticipated) and specifically those coded categories directly related to the satisfaction scales. Because the distributions of both sets of variables were significantly skewed, Spearman's rho, a non-parametric statistical test, was used for the correlations reported below.

\section{Expectations and satisfaction with 'Supervision'}

Supervision was a topic raised by only 13 of the 104 interviewees, and it accounted for only $14 \%$ of the comments made. However, negative mismatch codes were by far the most consistently related to the satisfaction with supervision scale with three of the four correlations reported being significant (see Table 4). It would seem that, for candidates, satisfaction with supervision was the most consistently linked with expectations/experience mismatches across a range of categories.

Table 4: Significant correlations between satisfaction and negative mismatch of expectations

\begin{tabular}{|l|c|c|c|c|}
\hline & \multicolumn{4}{|c|}{ EXPECTATION DIMENSIONS } \\
\hline $\begin{array}{l}\text { SATISFACTION } \\
\text { WITH: }\end{array}$ & $\begin{array}{c}\text { TASK: } \\
\text { ALL }\end{array}$ & $\begin{array}{c}\text { UNIVERSITY: } \\
\text { SUPERVISION }\end{array}$ & $\begin{array}{c}\text { PERSONAL: } \\
\text { EMOTIONAL }\end{array}$ & OVERALL \\
\hline Supervision & $\cdot$ & -0.291 & -0.295 & -0.288 \\
\hline Department/university & $\cdot$ & $\cdot$ & $\cdot$ & -0.212 \\
\hline Own preparation & $\cdot$ & $\cdot$ & -0.237 & $\cdot$ \\
\hline
\end{tabular}

\section{Expectations and satisfaction with the 'Department/university'}

The only significant relationship between candidate satisfaction with 'Department/university' was with their expectations summed across all three dimensions. The 55 candidates who made at least one comment that the reality of their candidature was worse than expected had lower scores on this scale than the other 49 candidates who made no negative comment. 


\section{Expectations and satisfaction with 'Own preparation'}

Of the 104 candidates in the sub-sample, 53 commented (negatively) that their personal expectations had not been met. These candidates had significantly lower scores related to satisfaction with their own preparation for candidature than the other 51 candidates who did not comment in this way.

All of the significant correlations between negative mismatch and satisfaction were negative indicating lower satisfaction, and three of the correlations were related to satisfaction with Supervision. This indicates, at the very least, that expectations that are not met in the 'University' dimension are related to low satisfaction with supervision, and the same tends to be the case for the 'Personal' dimension. In addition, negative mismatch in the 'Personal' dimension was related to lower satisfaction with 'Own preparation'. Mismatch in expectations with 'Task' was not significantly related to any of the three measures of satisfaction. Commonly used measures of satisfaction do not tend to focus on learning and the nature of the task. This may be an important omission because, as indicated above in the analysis of mismatch from the interviews, there were substantial unmet expectations around 'Task'. A further practical implication is the need for the development of an expectations instrument that can help identify more fully sources of candidate dissatisfaction.

\section{Strengths and Limitations}

In order to identify expectations early in candidature, access to $\mathrm{PhD}$ candidates in the first few weeks of enrolment would be ideal, with follow up 12-18 months later to determine subsequent experience. The candidates in this study were volunteers at different points in candidature and none earlier than six months when interviewed. However, the number of cases provided ample scope for ascertaining different dimensions of expectation and for gaining a clear impression of mismatch. The interview was framed around learning, and this may explain why there was lesser focus on expectations specific to supervision and more on doing the research than in other studies where the opposite occurs and supervision is given more prominence. The finding, however, is not out of kilter with recent literature on well-being. Juniper et al. (2012) show that, when given opportunity, students nominate research over supervision as a key focus for concern. Finally, while we acknowledge that the mismatch measure extracted from the interviews and used to perform the analyses with satisfaction was crude in statistical terms, the effect was to demonstrate connection between negative mismatch and low levels of satisfaction. The way forward, evident from the findings overall, is to construct, develop, and trial an instrument inclusive of all dimensions of expectation, to better test the link between expectations and satisfaction, well-being and learning behaviours. This is the next step in the team's research as outlined below.

\section{Discussion and Conclusion}

While research into the doctorate is growing rapidly, there are still many areas in need of further development to enhance understanding of the doctoral learner. Candidate expectations and the nature and consequences of mismatch between expectations and experience constitute one such strand. In previous research mismatch between expectations and experience has been looked at quite closely in relation to experience of supervision and academic match (Hair, 2009; Moxham et al., 2012; Spaulding \& Rockinson-Szapkiw, 2012) but lacks specific focus on learning about and doing research. To advance research into expectations in this context, we asked candidates in a telephone interview about their initial expectations and to reflect on whether their experience as learners or more generally mirrored what they expected. The analysis captured all references to expectations in the interview in context. The types of expectations nominated by the participants were captured in three main dimensions ('Task', 'University,' and 'Personal'). Most frequently

nominated were expectations about the 'Task', which was essentially what was involved (for ex- 
ample writing and data collecting), with some specific emphases on time and difficulty. Candidates also identified areas of expectation linked to 'University'. This included expectations of amount and type of support from supervisors and institution. 'Personal' expectations captured their state of mind as a learner and emotional dimensions of study, expectations of the future, and balancing study, work, and home life.

In addition to nominating areas of expectation, candidates had been asked to comment about their subsequent experience. These comments were examined to detect evidence of match or mismatch and the orientation of mismatch. More than one third of the 104 interviewees nominated instances of match. They indicated that doing a $\mathrm{PhD}$ was hard or challenging but no more or less than expected. There was a small group who indicated situations where the experience was better than expected (referred to in this paper as positive mismatch). The majority of comments, however, identified situations of negative mismatch, where things were not measuring up or were more difficult or challenging than candidates had expected. Bearing in mind that the interviews were undertaken in the context of learning, the primary source of mismatch for approximately half of those interviewed was in relation to the 'Task'. Supervision, which is arguably a closely related area, received relatively little emphasis in terms of stated expectations. While mentions of supervision were fewer than the authors anticipated given the emphasis in previous literature, when candidate satisfaction with supervision is examined in relation to comments about mismatch, it is evident that they are strongly indicative of low satisfaction - a finding that supports previous research that emphasizes the importance of supervision in student experience (Moxham et al., 2013; Pole et al., 1997; Zhao et al., 2007).

Doctoral study is irrefutably hard, and many seemed to underestimate the difficulty and other intellectual and emotional pressures. This accounts for the shock described by some candidates who may have already worked autonomously or had done preparatory degrees, yet found they were not as prepared as they had believed they were. Other authors have also pointed out that candidates are unable to envisage the demands of a PhD (Kandiko \& Kinchin, 2012). Helping them do this is clearly a priority.

Research has established that if doctoral candidate expectations are fulfilled, then students tend to be more satisfied with their program and are less likely to drop out (Bair \& Haworth, 2004). This paper explores initial expectations of doctoral candidates and links them with satisfaction in a way that expands insights into both, and in particular highlights that it is not possible to ignore expectations for another reason - candidate well-being. The scope for emotional challenge in doctoral degrees has been clearly identified in the literature (Juniper et al., 2012). A number of candidates said they had expected their emotions might be like a 'roller-coaster' but not with the intensity they actually experienced. There is now growing realization in the field (Juniper et al., 2012; White, 2013) that current satisfaction scales used to measure candidate experience in higher education are not taking into account the emotion and well-being of the candidate. As revealed in this study, emotional stress can arise from mismatch across a number of dimensions even by those who thought that it "would have been easier" (0146), "a little more structured" (0020), and did not expect the "kind of commitment and the focus that you have to have during the whole process" (0549).

In order to minimize the impact of mismatches between candidates' perceptions and experiences of the doctoral task, it is important for university induction programs to be more explicit about the task and the norms of experience. Candidates do not enter doctoral study with 'doctoral level thinking', this requires a developmental process, but what this process might entail is not often addressed with candidates (Kandiko \& Kinchin, 2012). Given the significant changes in cognitive development and the accompanying emotional experiences that candidates undergo, there needs to be an emphasis on how candidates can be supported in their learning to detect and address problematic expectations. Supervisors can play an important role here and need to be better in- 
formed about how these expectations manifest. The authors are currently developing such information for an induction package they will trial in conjunction with a new expectations questionnaire that will expand on the initial work of Bieschke (2000) and Hair (2006). The dimensions of expectation will include task, supervision, institution, personal/social experience, and future trajectory. Hair used his questionnaire as the prompt for discussion between supervisors and students early in candidature, and this approach has possibilities. We argue further that routinely collected satisfaction and progress report data can become important tools in candidate development if they are sufficiently sensitized to candidate expectations.

\section{References}

Bair, C., \& Haworth, J. (2004). Doctoral student attrition and persistence: A meta-synthesis of research. In J. C. Smart (Ed.), Higher education: Handbook of theory and research (pp. 481-534). The Netherlands: Kluwer Academic Publishers.

Barnett, J., Cropley, B., Hanton, S., \& Fleming S. (2013). Taking the plunge: Reflections on the decision to register for a doctorate. Journal of Hospitality, Leisure, Sport \&Tourism Education, 13, 123-131.

Bazeley, P. (2013). Qualitative data analysis: Practical strategies. London: Sage.

Bieschke, K. (2000). Factor structure of the Research Outcome Expectations Scale. Journal of Career Assessment, 8(3), 303-313.

Braun, V., \& Clarke, V. (2006). Using thematic analysis in psychology. Qualitative Research in Psychology, 3(2), 77-101.

Cantwell, R., Scevak, J., Bourke, S., \& Holbrook, A. (2012). Individual differences that affect the quality of learning in doctoral candidates. In M. Lawson \& J. Kirby (Eds.), Enhancing the quality of learning: Dispositions, instruction and learning processes (pp. 93-114). Cambridge, UK: Cambridge University Press.

Edwards, D., Bexley, E., \& Richardson, S. (2010). Regenerating the academic workforce: The careers, intentions and motivations of higher degree research students in Australia. Canberra, ACT: Department of Education, Employment and Workplace Relations.

Engebretson, K., Smith, K., McLaughlin, D., Seibold, C., Terrett, G., \& Ryan, E. (2008). The changing reality of research education in Australia and implications for supervision: A review of the literature. Teaching in Higher Education, 13(1), 1-15.

Gardner, S. (2009). Student and faculty attributions of attrition in high and low-completing doctoral programs in the United States. Higher Education, 58(1), 97-112.

Gardner, S. (2010). Keeping up with the Joneses: Socialization and culture in doctoral education at one third-tier institution. The Journal of Higher Education, 81(6), 658-679.

Gittings, G. (2010). The effect of student attributes and program characteristics on doctoral degree completion. PhD thesis, University of Louisville. Retrieved, March 15, 2014, from http://www.eric.ed.gov/ERICWebPortal/detail?accno=ED522895

Golde, C. (2005). The role of the department and discipline in doctoral student attrition: Lessons from four departments. The Journal of Higher Education, 76(6), 669-700.

Hair, M. (2006). Superqual: A tool to explore the initial expectations of PhD students and supervisors. Active Learning in Higher Education, 7(1), 9-23.

Haksever, A., \& Manisali. E. (2000). Supervision requirements of PhD students: The case of construction. European Journal of Engineering Education, 25(1), 19-32.

Harman, G. (2002). Producing PhD graduates in Australia for the knowledge economy. Higher Education Research \& Development 21(2), 179-190. 
Hoskins, C., \& Goldberg, A. (2005). Doctoral student persistence in counselor education programs: Student-program match. Counselor Education and Supervision 44(3), 175-188.

Juniper, B., Walsh, E., Richardson, A., \& Morley, B. (2012). A new approach to evaluating the well-being of PhD research students. Assessment \& Evaluation in Higher Education, 37(5), 563-576.

Kandiko, C., \& Kinchin, I. (2012). 'What is a doctorate? A concept-mapping analysis of process versus product in the supervision of lab-based PhDs. Educational Research, 54(1), 3-16.

Klein, H., \& Rowe, F. (2008). Marshaling the professional experience of doctoral students: A contribution to the practical relevance debate. MIS Quarterly, 32(4), 675-686.

Könings, K., Brand-Gruwel,S., van Merriënboer, J., \& Broers, N. (2008). Does a new learning environment come up to students' expectations? A longitudinal study. Journal of Educational Psychology, 100(3), $535-548$.

Lindn, J., Ohlin, M., \& Brodin, E. (2013). Mentorship, supervision and learning experience in PhD education. Studies in Higher Education, 38(5), 639-662.

McAlpine, L, Paulson, J., Consalves, A., \& Jazvac-Martek. M. (2012). 'Untold' doctoral stories: Can we move beyond cultural narratives of neglect? Higher Education Research \& Development, 31(4), 511523.

McCormack, C. (2004). Tensions between student and post-graduate research. Studies in Higher Education, 29(3), 319-334.

Moxham, L., Dwyer, T., \& Reid-Searl, K. (2013). Articulating expectations for PhD candidature upon commencement: Ensuring supervisor/student 'best fit'. Journal of Higher Education Policy and Management, 35(4), 345-354.

Nicholson, L., Putwain, D., Connors, L., \& Hornby-Atkinson, P. (2013). The key to successful achievement as an undergraduate student: confidence and realistic expectations? Studies in Higher Education, $38(2), 285-298$.

Nyquist, J. D., Manning, L., \& Wulff, D. H. (1999). On the road to becoming a professor: The graduate student experience. Change: The Magazine of Higher Learning, 31(3), 18-27.

Pearson, M. (2012). Building bridges: Higher degree student retention and counselling support. Journal of Higher Education Policy and Management, 34(2), 187-199.

Pearson, M., Cumming, J., Evans, T., MacCauley, P., \& Ryland, K. (2011). How shall we know them? Capturing the diversity of difference in Australian doctoral candidates and their experiences. Studies in Higher Education, 36(5), 527-542.

Pole. C., Sprokkereef, A., Burgess, R., \& Lakin, E. (1997). Supervision of doctoral students in the natural sciences: Expectations and experiences. Assessment \& Evaluation in Higher Education, 22(1), 49-63.

Russo, G. (2011). Aspirations and anxieties. Nature, 475, 533-535.

Spaulding, L., \& Rockinson-Szapkiw (2012). Hearing voices: Factors doctoral candidates attribute to their persistence. International Journal of Doctoral Studies, 7, 199-219. Retrieved from http://ijds.org/Volume7/IJDSv7p199-219Spaulding334.pdf

Teddlie, C., \& Tashakkori, A. (2003). Major issues and controversies in the use of mixed methods in the social and behavioural sciences. In A. Tashakkori \& C. Teddlie (Eds.), Handbook of mixed methods in social \& behavioural research (pp. 3-50). Thousand Oaks, CA: Sage.

Tennant, M. (2008). Regulatory and quality assurance regimes in doctoral education: fostering innovation and risk or standardization and safety? Proceedings of the Australian Universities Quality Forum, pp.127-131. Retrieved 15 February, 2014, from https://www.academia.edu/2314877/Regulatory and quality assurance regimes in doctoral_educatio n fostering innovation and risk_or_standardization and safety_i 
Trigwell, K., \& Dunbar-Goddet, H. (2005). The research experience of postgraduate research students at the University of Oxford. Institute for the Advancement of University Learning, University of Oxford. Retrieved 15 February, 2014 from http://www.learning.ox.ac.uk/media/global/wwwadminoxacuk/localsites/oxfordlearninginstitute/docu ments/overview/research/publications/PGRreport.pdf

Watts, J. (2009). From professional to PhD student: Challenges of status transition. Teaching in Higher Education, 14(6), 687-691.

White, C. J. (2013). Higher education emotions: A scale development exercise. Higher Education Research \& Development, 32(2), 287-299.

Ylijoki, O.-H. (2013). Boundary-work between work and life in the highspeed university. Studies in Higher Education, 38 (2), 242-255.

Zhao, C., Golde, C., \& McCormick, A. (2007). More than a signature: How advisor choice and advisor behaviour affect doctoral student satisfaction. Journal of Further and Higher Education, 31(3), 263281.

\section{Biographies}

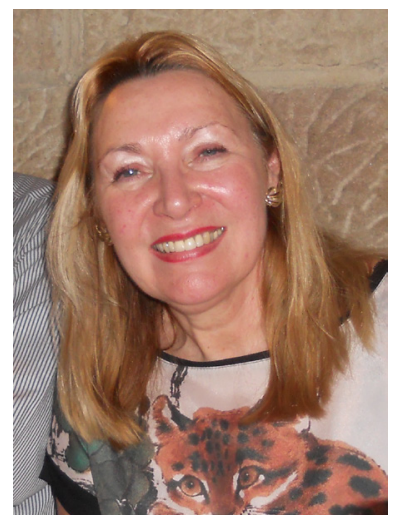

Allyson Holbrook (PhD) is Professor of Education and Director of the Centre for the Study of Research Training and Innovation (SORTI), The University of Newcastle, Australia. Her research interests focus on doctoral level assessment, quality, and how research learning occurs. A second prominent strand examines how new knowledge is supported, created, managed, judged, disseminated, and applied by professional groups. Allyson has been awarded five Australian Research Council Discovery Grants in the area of doctoral candidature and assessment, and is currently Chair of The University of Newcastle Human Research Ethics Committee.

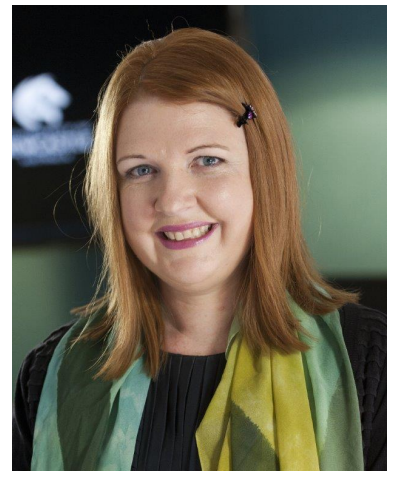

Kylie Shaw $(\mathrm{PhD})$ is an Early Career Researcher and a Senior Lecturer in Literacy, Educational Psychology and ICT. She is Deputy Director of the Centre for the Study of Research Training and Innovation (SORTI) at The University of Newcastle and the Convenor of the Doctoral Education Special Interest Group for the Australian Association of Research in Education (AARE). Kylie recently completed her PhD on a cross-disciplinary exploration of students' experience of Honours, developing a construct of 'research preparedness' and tracking the highs and lows of the research journey. She is a Chief Investigator on a recently awarded Australian Research Council Discovery Grant. 

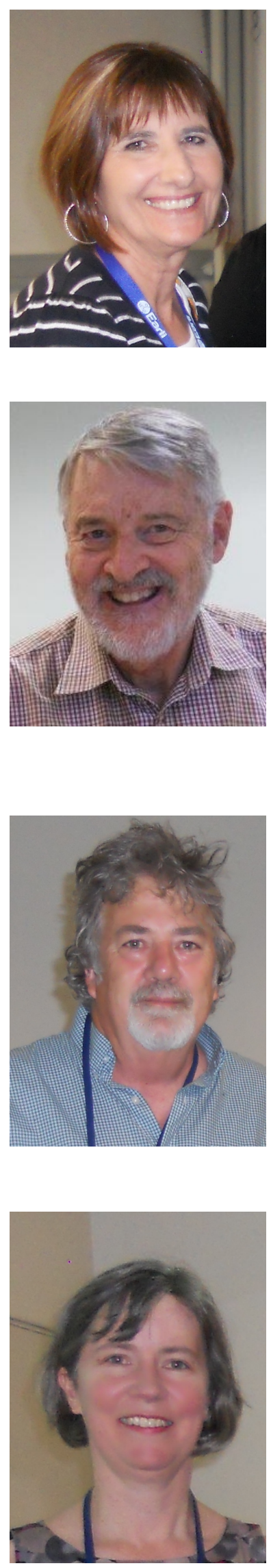

Jill Scevak $(\mathrm{PhD})$ is a Senior Lecturer, Faculty of Education \& Arts and a member of the Centre for the Study of Research Training and Innovation (SORTI) at The University of Newcastle. Jill is an Educational Psychologist, practicing psychologist, and is Chair of the Newcastle Branch of the Australian Psychological Society. Research interests are the influence of cognitive, metacognitive, affective and sociocultural factors on development of discipline knowledge and higher order thinking in $\mathrm{PhD}$ students. She played a key role in the development of a program of research into the metacognitive profile of $\mathrm{PhD}$ candidates and is a Chief Investigator on two Australian Research Council Discovery Grants.

Sid Bourke (PhD) is Professor Emeritus in the Faculty of Education \& Arts, The University of Newcastle, Australia. His current research interests include educational assessment, particularly of affective outcomes, and the development and application of quantitative research methods. More specifically, his major research focus and recent publications are on $\mathrm{PhD}$ candidature, completion times and attrition, and thesis assessment. He has been awarded five Australian Research Council Discovery Grants in the area of doctoral candidature and assessment.

Dr Robert Cantwell $(\mathrm{PhD})$ is a Senior Lecturer in the Faculty of Education \& Arts and a member of the Centre for the Study of Research Training and Innovation (SORTI) at The University of Newcastle. Robert specialises in the development and applications of learning theory to professional and higher learning. He has a specific interest in the development of metacognitive theory. He has been a Chief Investigator in Australian Research Council Discovery Grants and Office of Learning and Teaching (Carrick) Grants.

Ms Janene Budd is a Clinical Psychologist with many years of experience as a clinician in the Public and Private sectors. She has also worked on Community Health and Behavioural Medicine research projects and was the Project Manager for the current study. Janene is currently completing her $\mathrm{PhD}$ in Educational Psychology with a research project investigating the self-monitoring of doctoral research students. 